\title{
Optimal control of pitch angle of large wind turbine based on speed differential
}

\author{
Xin $G A O^{l}$, Xiaoyu $W A N G^{1 *}$, Jiahuan $H E^{l}$ \\ ${ }^{1}$ Northwest Electric Power Test and Research Institute, China Datang Corporation Science and Technology Research Institute Co., Ltd, \\ 710021 Xi'an, Shaanxi, China.
}

\begin{abstract}
In order to improve the power output of wind turbine at low wind speed, this paper studies the aerodynamic performance of wind turbine blades at different installation angles. It is found that the optimal pitch angle of wind turbine can be switched between different installation angles when wind speed changes by introducing wind turbine speed differential feedback signal in PI controller of variable pitch, so as to track the optimal wind energy utilization coefficient The purpose of improving wind turbine power output. In order to verify the reliability of the analysis results, bladed is used to simulate the model of a $1.5 \mathrm{MW}$ unit with pitch differential control signal. At the same time, the research results are applied to the actual operation of the unit. The results show that the power curve of the wind turbine unit at low wind speed can be improved and the annual power generation can be increased by $1.24 \%$.
\end{abstract}

\section{Introduction}

The main control technology of wind turbine is variable pitch and variable speed control technology ${ }^{[1]}$. The purpose of control is to achieve maximum wind energy capture on the premise of preventing the unit from overload. In the actual operation process, the total control strategy of wind turbine is that when the wind speed is lower than the rated wind speed, the blade pitch angle is always maintained at $0^{\circ}$ and the maximum wind energy is captured by adjusting the wind turbine speed $^{[2]-[4]}$; when the wind speed is higher than the rated wind speed, the wind turbine speed remains unchanged. By adjusting the pitch angle, the constant power output curve is tracked to ensure the stable power output ${ }^{[5]}$.

In this paper, based on the existing wind turbine control technology, through the analysis of the aerodynamic characteristics of wind turbine blades, it is found that when the wind speed is low, fine tuning the blade pitch angle can improve the aerodynamic performance of the blade ${ }^{[6]-[7]}$. Therefore, this paper introduces low wind speed pitch control strategy into the wind turbine controller to improve the generation efficiency of wind turbine at low wind speed.

\section{Small wind pitch strategy}

\subsection{The relationship between wind turbine power factor, blade tip speed ratio and pitch angle}

As shown in Figure 1, the curve cluster between wind energy utilization coefficient $C_{p}$ and tip speed ratio $\lambda$ of a certain type of $1.5 \mathrm{MW}$ wind turbine at different installation angles $\beta$ is studied in this paper . According to the selection principle of optimal $C_{p}-\lambda$ : $C_{p \max }$ should be high, the top of $C_{p}-\lambda$ curve should be flat, and $\lambda$ should be as small as possible. According to Figure 1, the optimal pitch angle of the blade is $0^{\circ}$, the corresponding optimal $C_{p}$ is 0.48 , and the optimal tip speed ratio $\lambda$ is 8.5 . Therefore, the optimal pitch angle of this blade should be $\beta_{0}=0^{\circ}$.

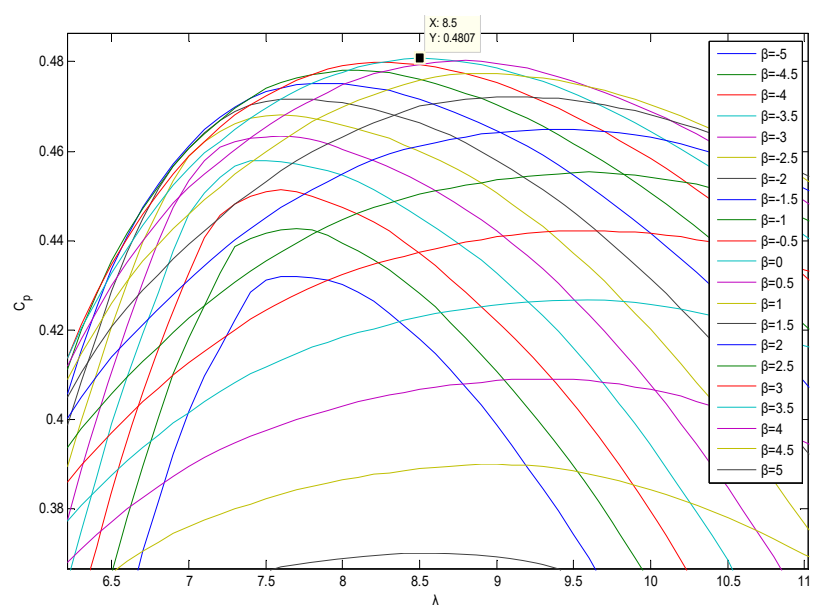

Figure1. Clusters of $C_{p}-\lambda$ curves for a certain type of blade at different installation angles $\beta$

When the wind turbine is running at low wind speed, the blade angle is set to the optimal installation angle. (The curve of $\beta_{0}=0^{\circ}$ in Figure 1). Tip speed ratio:

$$
\lambda=\frac{\omega R}{v}
$$

\footnotetext{
* Corresponding author: 279155456@qq.com
} 
Where: $\omega$-Angular speed of wind wheel; R-Wind wheel radius; $v$-Upstream wind speed.

Due to the great inertia of the impeller, the change in impeller speed is far behind the change in wind speed. When the wind speed suddenly increases, $\lambda$ decreases. In the case of a constant pitch angle, the state of the fan will change from point A to point D in Figure 2. Obviously, if the pitch angle can be adjusted to $\beta=-1^{\circ}$ at this time, the state of the wind wheel will switch to point $C$ in the figure. At the same tip speed ratio, the $C_{p}$ value $(\lambda)$ at point $\mathrm{C}$ is significantly greater than that at point $\mathrm{B}$ (0.469). When the speed is gradually stabilized, the wind machine will return to point $\mathrm{A}$ and continue to maintain the optimal power coefficient $(0.483)$. That is, in the process of sudden increase in wind speed, when $\beta=0^{\circ}$, the wind machine will run along the $C_{p}-\lambda$ curve of $\beta=0^{\circ}$, that is, along the curve ABD. When the speed of the wind wheel stabilizes, then return from point D Point A, running along the curve DBA at this time, that is, the running trajectory is ABD-DBA during a wind speed change. Now when the wind speed increases, the optimal pitch angle is adjusted to $-1^{\circ}$, that is, the actual operating curve is $\mathrm{ABC}$. When the wind speed is stable, it runs along the curve $\mathrm{CBA}$, that is, the running trajectory is $\mathrm{ABC}-\mathrm{CBA}$ during a wind speed change. Obviously, the $C_{p}$ value of the trajectory ABC-CBA in the curve $\mathrm{BC}$ is significantly higher than the curve $\mathrm{BD}$.

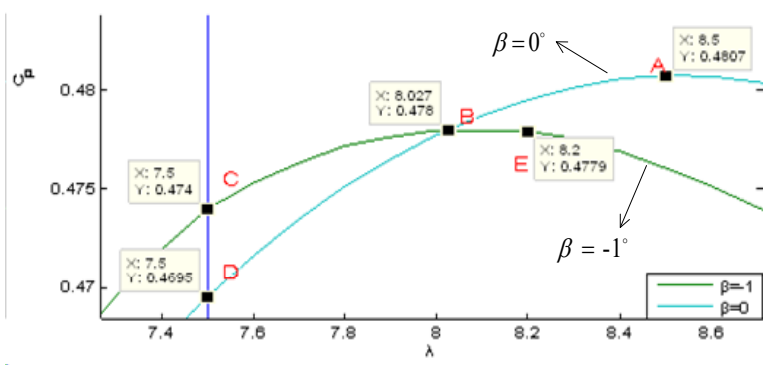

Figure 2. After partial amplification

Based on the above analysis, this strategy can be realized by introducing the feedback signal of wind turbine speed differential into the optimal pitch angle of wind turbine.

\subsection{Design of Optimized Controller for Pitch Angle}

(1) Extraction of the differential value of wind wheel speed

There are many ways to obtain the differential value of the rotor speed $\omega$. The following uses "non-linear fastest differential tracker", the formula is as follows:

$$
\left\{\begin{array}{l}
x_{1}(t+h)=x_{1}(t)+h \times x_{2}(t) \\
x_{2}(t+h)=x_{2}(t)+h \times u,|u| \leq r
\end{array}\right.
$$

In Equation5, there is

$$
u=f s t\left(x_{1}(t)-v(t), x_{2}(t), r, h_{0}\right)
$$

$$
\begin{gathered}
d=r \times h_{0} ; d_{0}=d \times h_{0} \\
y=x_{1}-v(t)+h_{0} \times x_{2} \\
a_{0}=\sqrt{d_{2}+8 \times r \times|y|} \\
a=\left\{\begin{array}{l}
x_{2}+\left(a_{0}-d\right) \times \operatorname{sgn}(y) / 2,|y|>d_{0} \\
x_{2}+y / h_{0},|y| \leq d_{0}
\end{array}\right. \\
f_{s t}=-\left\{\begin{array}{l}
r \times a / d,|a| \leq d \\
r \times \operatorname{sgn}(a),|a|<d
\end{array}\right.
\end{gathered}
$$

Where:h-Integration step; r-Speed factor ; $x_{1}(t)$ - the tracking speed of variable to the tracked quantity; $x_{2}(t)$ the differential signal of variable $x_{1}(t) ; h_{(0)}$ the filtering factor.By adjusting the size of the speed factor and the filter factor, the tracking speed and filtering control can be realized.

The fastest differential tracker is a way to quickly track the original signal, at the same time it can reasonably extract the derivative of the signal and can better attenuate the noise interference in the signal.

(2) Design of blade optimal controller

Now use the discretized "non-linear fastest differential tracker" to extract the differential signal in the rotor speed, according to the above analysis of the optimization principle of the impeller pitch angle, the variable pitch PI controller is designed. The block diagram is shown in Figure 3.

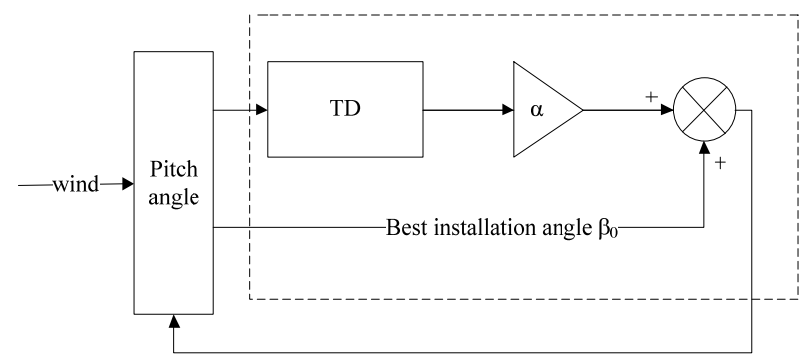

Figure 3. Pitch angle optimization controller

The optimized pitch angle controller is shown in the dashed frame in Figure 3, which is composed of the differential value of the wind wheel speed extracted by the differential tracker multiplied by the adjustment factor $(\alpha \omega)$ and the optimal installation angle of the blade $\left(\beta_{0}\right)$. The final pitch angle for optimized pitch control is as follows:

$$
\beta=\beta_{0}-\alpha \dot{\omega}
$$

\section{Simulation results}

\subsection{Simulation of wind speed step change}

(1) Step wind model 
In order to ensure the application effect of the wind turbine speed differential feedback signal, this paper introduces the control strategy of the wind turbine speed differential feedback signal to the pitch angle PI controller, and uses VC6.0 to generate DLL. The external controller interface of bladed software is used to call the controller DLL file for simulation. The basic parameters of simulation wind turbine are as follows:

Table 1 the Basic parameters

\begin{tabular}{|c|c|}
\hline parameter & numerical value \\
\hline Rotor diameter $(\mathrm{m})$ & 82 \\
\hline Rated power $(\mathrm{KW})$ & 1500 \\
\hline Rated torque $(\mathrm{Nm})$ & 8550 \\
\hline Rated speed of high speed shaft $(\mathrm{rpm})$ & 1770 \\
\hline Gear box ratio & 104.2 \\
\hline Number of blades & 3 \\
\hline
\end{tabular}

Using the step wind model simulation, that is, the wind speed suddenly increased from $6 \mathrm{~m} / \mathrm{s}$ to $7 \mathrm{~m} / \mathrm{s}$ at $20 \mathrm{~s}$ in the simulation process, and the wind speed suddenly decreased from $7 \mathrm{~m} / \mathrm{s}$ to $6 \mathrm{~m} / \mathrm{s}$ at $120 \mathrm{~s}$, and the total simulation time was 200s. See Figure 4 for changes in wind speed. Simulate "Run powprod-normal" and "Run powprod-smallpitch" to calculate the same wind speed conditions twice.

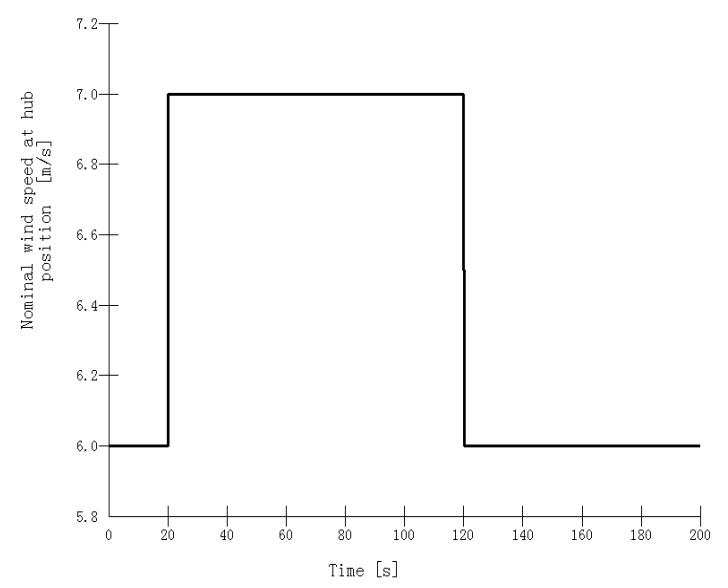

Figure 4. Wind speed change

(2) simulation result

Figure 5 is the simulation calculation result after adding the wind speed condition shown in Figure 4. It can be seen from Figure 5 that under the $6-7 \mathrm{~m} / \mathrm{s}$ wind speed condition, the blades of the normal pitch system have been kept at 0 , and the "small wind" is added. The pitch angle after "Pitching Strategy" will automatically adjust as the wind speed changes.

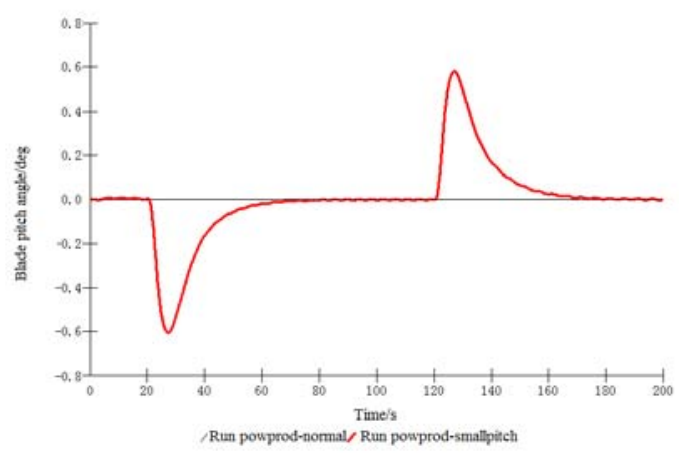

Figure 5. Pitch angle change

Figure 6 is a graph of the wind turbine power change in this process. It can be seen that the reason that the power increases before $40 \mathrm{~s}$ and decreases after 40 is caused by the actual cross point in Figure 2 may deviate from point $\mathrm{B}$, so a reasonable choice of a is especially important for simulation results.

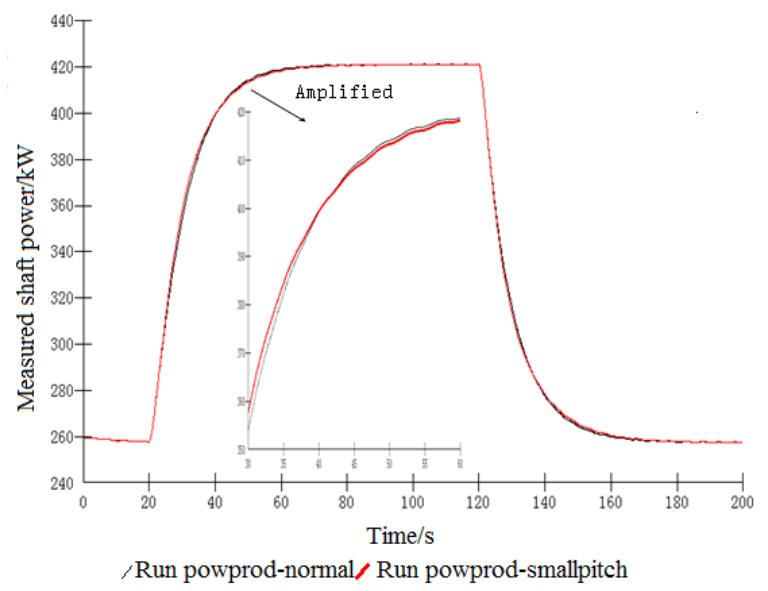

Figure 6. Power change

Use Bladed's built-in statistical function to make statistics on the output shaft power in Figure 6, the statistical results are shown in Table 2. Mean is the average value of power, and Std. Dev (standard deviation) reflects the degree of dispersion of power from the average value, that is, the fluctuation of power. In no of points (blade), the output of bladed is set to output a point, so 10000 points equals 200s. The average result shows that the power increases after adding the small wind pitch strategy.

Table2. Power Statistics under Step Wind

\begin{tabular}{|c|c|c|c|c|}
\hline Channel & Mean & Std.Dev & Units & $\begin{array}{c}\text { No of } \\
\text { points }\end{array}$ \\
\hline $\begin{array}{c}\text { Run powprod- } \\
\text { normal }\end{array}$ & 338705 & 73620.9 & $\mathrm{~W}$ & 10000 \\
\hline $\begin{array}{c}\text { Run powprod- } \\
\text { smallpitch }\end{array}$ & 338827 & 73456.7 & $\mathrm{~W}$ & 10000 \\
\hline
\end{tabular}

\subsection{Turbulent wind simulation}

The change in wind speed is mainly caused by the intensity of turbulence. Table 3 is the basic parameters for determining the level of wind turbines specified in 
the IEC61400-1: 2005 standard, where $I_{\text {ref }}$ represents the level of turbulence characteristics. It gradually decreases from A to C. If calculated according to class A grade, the representative value of turbulence intensity is $26.93 \%$ when the wind speed is $6 \mathrm{~m} / \mathrm{s}$.

Table3. Basic parameters for wind turbine classes

\begin{tabular}{|c|c|c|c|}
\hline Wind turbine class & I & II & III \\
\hline Vref $(\mathrm{m} / \mathrm{s})$ & 50 & 42.5 & 37.5 \\
\hline A Iref(-) & & 0.16 & \\
\hline B $\quad$ Iref(-) & & 0.14 & \\
\hline C $\quad$ Iref(-) & & 0.12 & \\
\hline
\end{tabular}

The simulation chooses a reasonable a value, set the wind speed to $6 \mathrm{~m} / \mathrm{s}$, sets the turbulence intensity to $26.93 \%$, and performs 10 min turbulent wind simulation. The change of the given wind speed is shown in Figure 7, the change of the impeller pitch angle is shown in Figure 8 , the power change is shown in Figure 10, use Bladed counts the power changes in Figure 9, and the results are shown in Table 4. The mean calculation results show that the power has increased by $0.557 \%$.

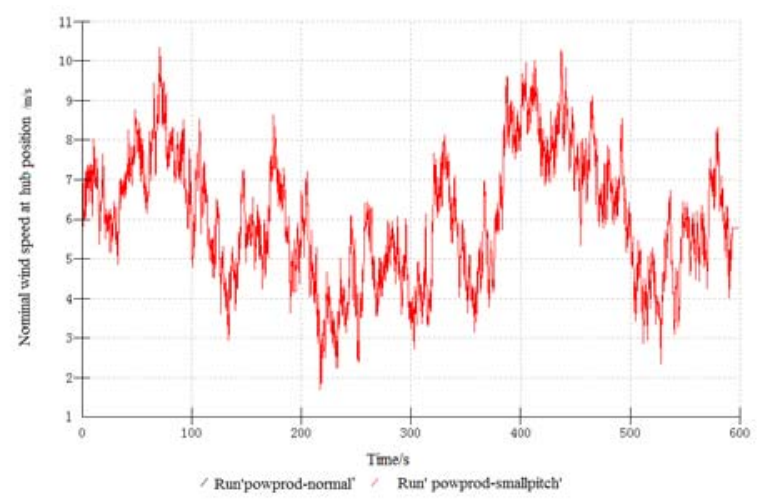

Figure 7. Turbulence wind speed change

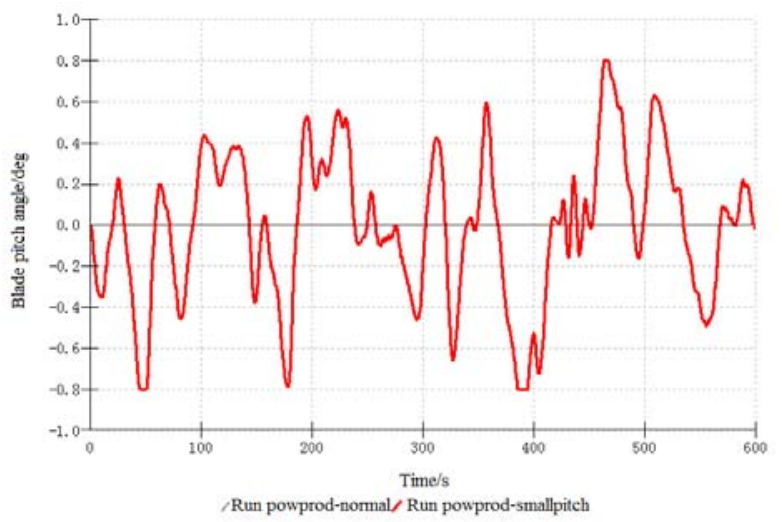

Figure 8. Pitch angle variation under turbulent wind speed

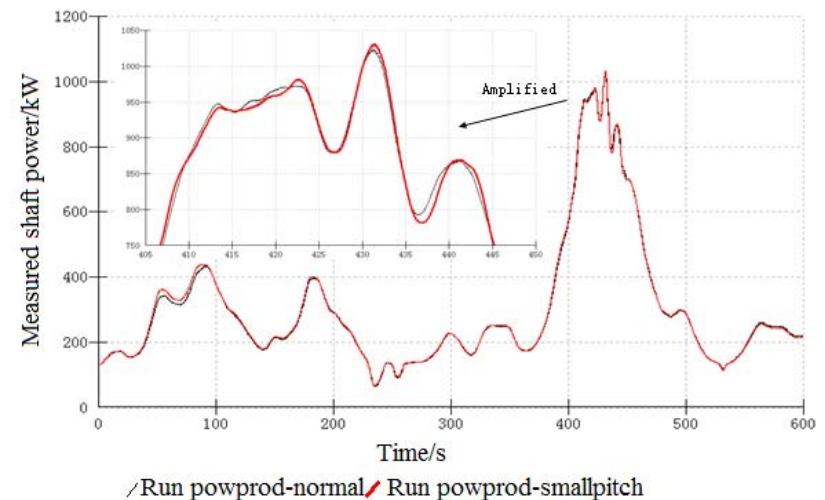

Figure 9. Power variation under turbulent wind speed

Table.4 Turbulence wind power for 10 minutes

\begin{tabular}{|c|c|c|c|c|}
\hline Channel & Mean & Std.Dev & Units & $\begin{array}{c}\text { No of } \\
\text { points }\end{array}$ \\
\hline $\begin{array}{c}\text { Run powprod- } \\
\text { normal }\end{array}$ & 298374 & 198426 & W & 30000 \\
\hline $\begin{array}{c}\text { Run powprod- } \\
\text { smallpitch }\end{array}$ & 300037 & 198831 & W & 30000 \\
\hline
\end{tabular}

\section{4 practical application}

In order to verify the application effect of introducing speed differential control signal into large-scale wind turbine, this paper applies the research results to the wind turbine studied. The operating environment conditions of the unit are shown : Location altitude: $1600 \mathrm{~m}$; Annual average air density: $1.03 \mathrm{~g} / \mathrm{m} 3$; ambient temperature: $-22.5-34.7^{\circ} \mathrm{C}$ 。

(1) Field data acquisition after application

The SCADA data of 30 seconds operation in low wind speed section is extracted by introducing speed differential control signal unit, as shown in Figure 10,Figure 11,Figure 12,Figure 13.

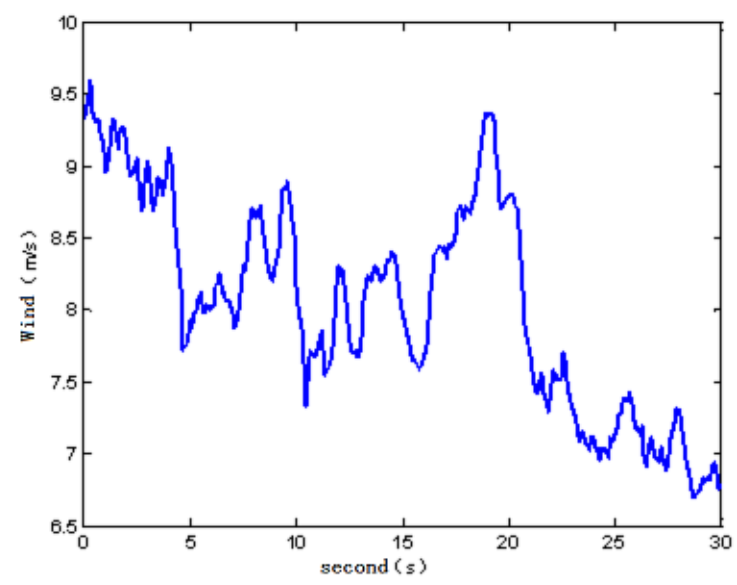

Figure10. Wind Speed 


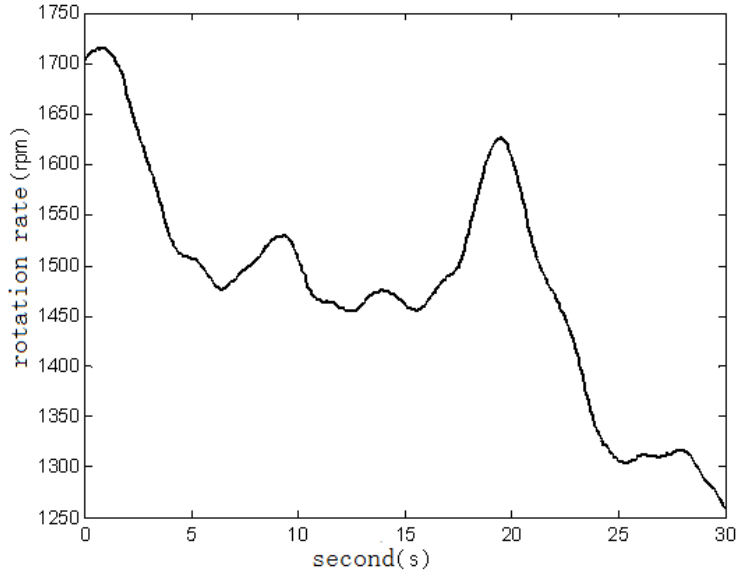

Figure11.Generator speed

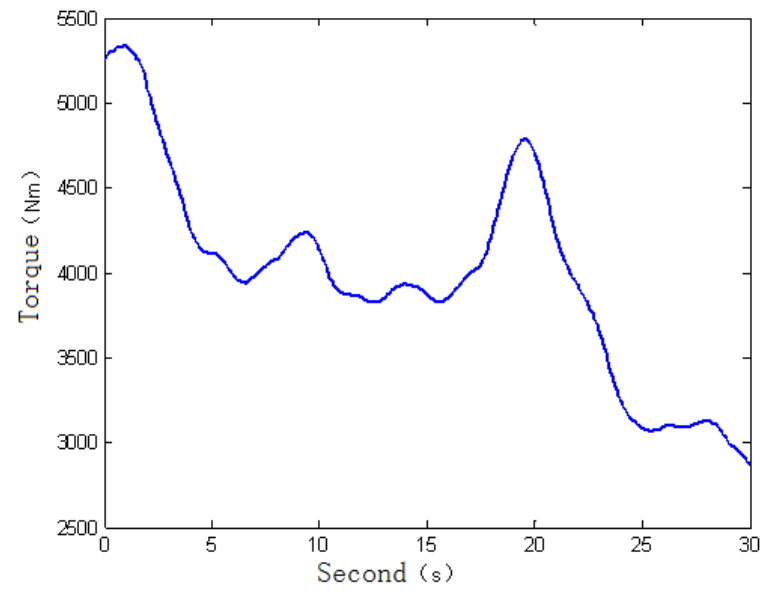

Figure12.Torque setting

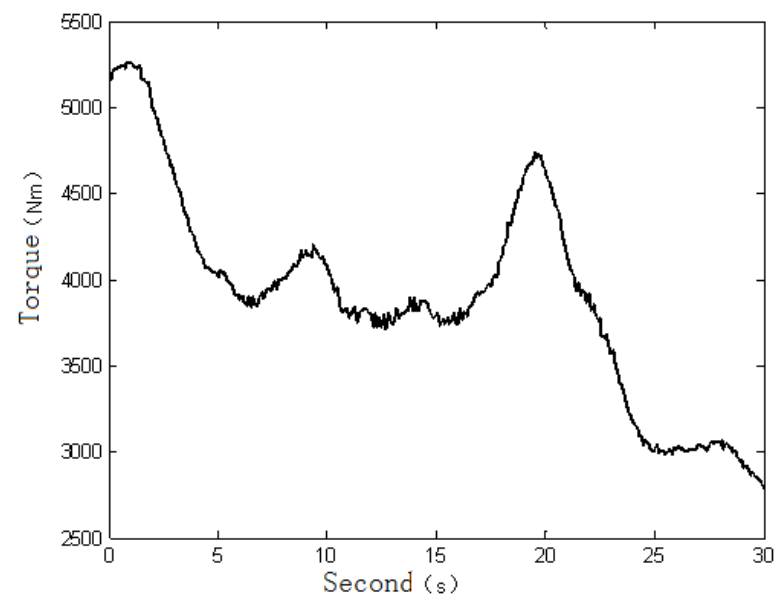

Figure13 Actual torque value

It can be seen from the figure 14-17 that during this period, the wind speed fluctuates below the rated wind speed, and the blade pitch angle fluctuates in the range of $0^{\circ}$ to $-0.5^{\circ}$ which is different from the traditional pitch control strategy, that is, when the wind speed is below the rated wind speed, the blade is always at the optimal installation angle of $0^{\circ}$.

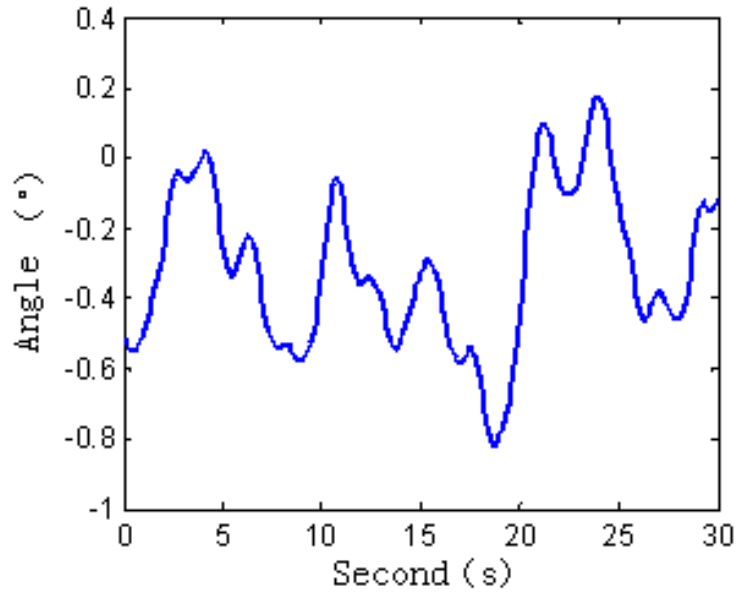

Figure14 Given value of pitch angle

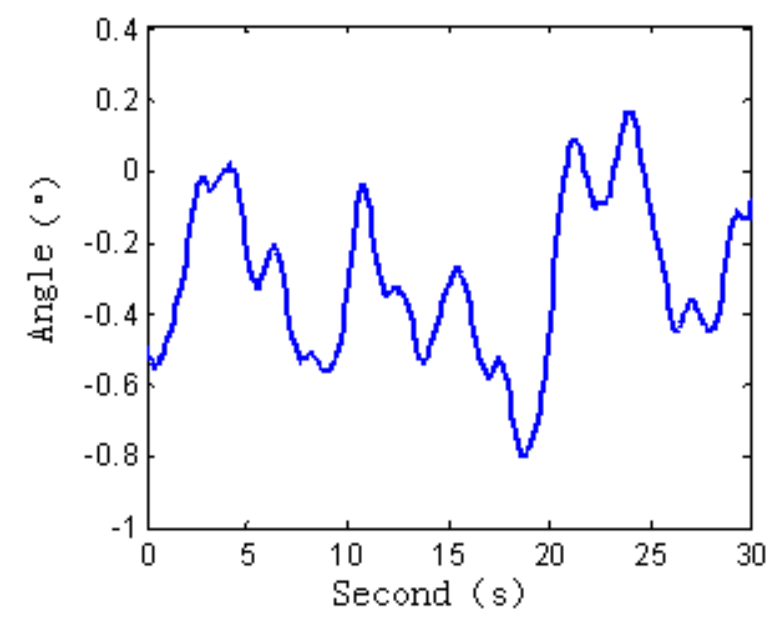

Figure15 Blade 1 pitch angle

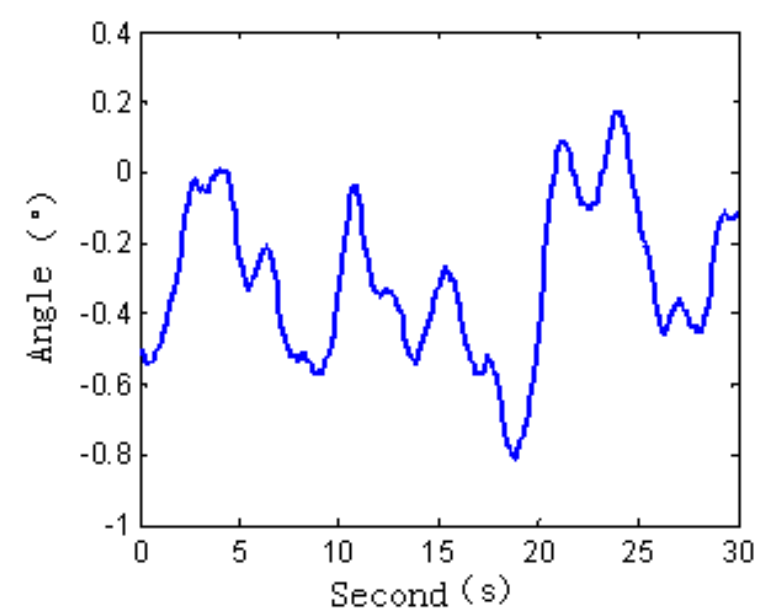

Figure16 Blade 1 pitch angle 


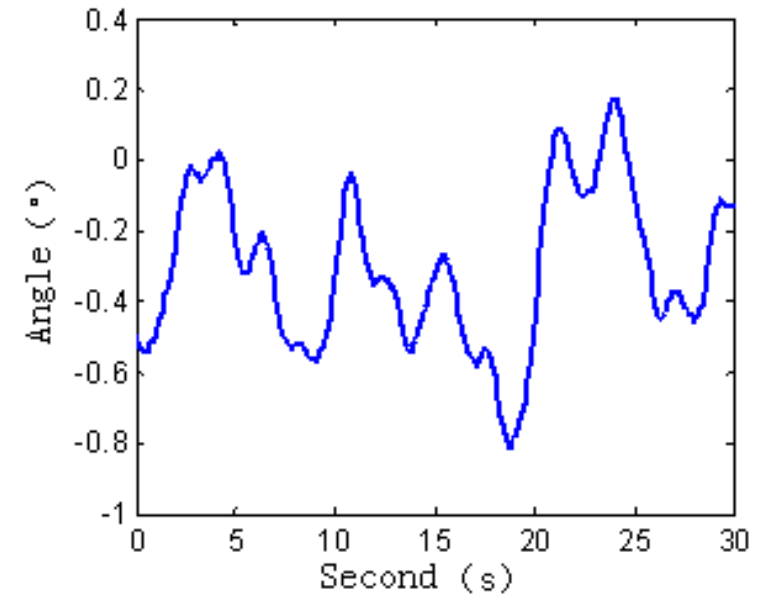

Figure17 Blade 1 pitch angle

(2) Unit power curve and power generation after application

The power curves of different stages before and after the application of the unit are selected. It can be seen from Figure 18 below: the power curve of the unit after transformation has been improved in the low wind speed section.

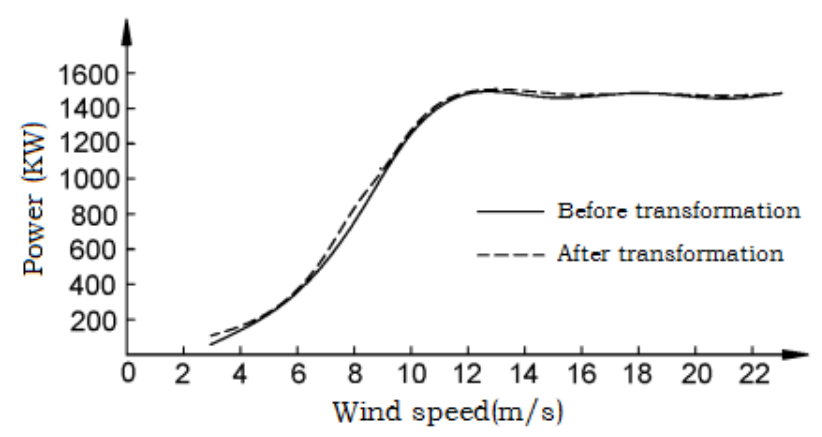

Figure 18 power curve of unit before and after modification

According to the theoretical power generation calculation method provided by GBT 18451.2-2012. It can be calculated according to the wind speed distribution and the measured power curve. The calculation formula of annual power generation is as follows:

$$
\begin{gathered}
A E P=N_{h} * \sum_{i=1}^{N}\left[F\left(V_{i}\right)-F\left(V_{i=1}\right)\right]\left(\frac{P_{i=1}+p_{i}}{2}\right) \\
F_{(V)}=1-\exp \left[-\frac{\pi}{4}\left(\frac{V}{V_{\text {ave }}}\right)^{2}\right]
\end{gathered}
$$

Where $A E P$ is the annual power generation, kW.h; $N_{h}$ is the annual generation time, $\mathrm{h} ; n$ is the number of intervals; $V_{i}$ is the annotated average wind speed in the interval, $\mathrm{m} / \mathrm{s} ; P_{\mathrm{i}}$ is the standardized output power in the ith interval, $\mathrm{kW} ; F_{(V)}$ is the cumulative probability distribution function of wind speed; $V$ is the wind speed, $\mathrm{m} / \mathrm{s}$.

\section{Conclusion}

After the relevant data are brought into the calculation, it can be seen that through the application of small wind pitch logic, the annual power generation of wind turbine is increased by $1.25 \%$, and the improvement effect is obvious.

In this paper, the low wind speed pitch control strategy is introduced into the wind turbine controller; Through numerical simulation analysis and field application, it can be seen that:

(1) The low wind speed pitch control strategy is in line with the theory of blade aerodynamic characteristics. In the SCADA data of the unit after application, it can be seen that the pitch angle changes from $0^{\circ}$ to $-1^{\circ}$ at low wind speed.

(2) After adding the low wind speed pitch control strategy, the power curve at low wind speed is improved, and the annual power generation of wind turbine can be increased by $1.24 \%$.

\section{References}

1. Complexity Research; Research on Complexity Research Detailed by Researchers at National School of Applied Sciences (Optimal Fault Tolerant Control of Large-Scale Wind Turbines in the Case of the Pitch Actuator Partial Faults)[J]. Journal of Technology, 2020.

2. Younes Ait El Maati, Lhoussain El Bahir, Kiyong Oh. Optimal Fault Tolerant Control of Large-Scale Wind Turbines in the Case of the Pitch Actuator Partial Faults[J]. Hindawi, 2020.

3. Shokoofeh Abbaszadeh, Stefan Hoerner,Thierry Maître,Roberto Leidhold.Experimental investigation of an optimised pitch control for a vertical-axis turbine[J]. The Institution of Engineering and Technology, 2019, 13(16).

4. Energy-Wind Turbines; Researchers from Shanghai Jiao Tong University Report Findings in Wind Turbines (An Optimal Power-decoupling Control Strategy Between Torque and Pitch Controllers for Variable-speed Pitch-regulated Wind Turbines)[J]. Energy Weekly News,2019.

5. Sebastiaan Paul Mulders,Atindriyo Kusumo Pamososuryo, Gianmarco Emilio Disario, JanWillem van Wingerden. Analysis and optimal individual pitch control decoupling by inclusion of an azimuth offset in the multiblade coordinate transformation[J]. Wind Energy, 2019, 22(3).

6. Zhijian Huang, Yanji Liu,Huan Zheng, Shengtang Wang, Jie Ma,Yihua Liu. A self-searching optimal ADRC for the pitch angle control of an underwater thermal glider in the vertical plane motion[J]. Elsevier Ltd, 2018, 159. [35]

7. H. Tourajizadeh, M. Rezaei, A. H. Sedigh. Optimal Control of Screw In-pipe Inspection Robot with Controllable Pitch Rate[J]. Springer Netherlands, $20[36] 18,90(3-4)$. 